Елена Маркова

Российский государственный университет им. А. Н. Косыгина (Россия)

Кафедра русского языка как иностранного

Католический университет в г. Ружомберке (Словакия)

Кафедра иностранных языков

Elena-m-m@mail.ru
УДК 811.161.1'374

https://doi.org/10.18485/slavistika.2020.24.2.19

прегледни рад

примљено 02.03.2020.

прихваћено за штампу 18.09.2020.

\title{
УЧЕБНЫЙ СЛОВАРЬ УНИВЕРБАТОВ СОВРЕМЕННОГО РУССКОГО ЯЗЫКА: НОВИЗНА, СТРУКТУРА, ПРИНЦИПЫ ОПИСАНИЯ
}

В статье речь идёт о широко распространенном в последнее время языковом явлении - универбации, представленной не только в устной речи (на телевидении, радио, в живом общении), но и на страницах газет и журналов. Активное и повсеместное распространение этого явления в наши дни, вызванное усилением тенденции к экономии языковых усилий и языковых средств, активизация универбации вызвали потребность в создании словаря универбатов. В статье рассматриваются разные точки зрения на явление универбации и определяется авторское видение этого явления, положенное в основу отбора языковых фактов в словарь. Систематизируются модели и деривационные средства создания универбатов, приводятся основные тематические группы, анализируется их стилистическая принадлежность и функционирование. Автором подчеркивается стилистически сниженный, разговорный характер большинства рассматриваемых в словаре новообразований, нередко наличие в них эмоционально-оценочной составляющей и выражается мнение о сохранении продуктивного характера рассматриваемой модели и постоянном пополнении словаря.

Ключевые слова: современный русский язык, тенденции развития, способы словообразования, универбация, словари.

The article discusses a recent mass phenomenon of language - univerbation, found not only in speech (television, broadcasting, live communication), but also in the pages of newspapers and magazines. The widespread occurrence of this phenomenon today, caused by the growing tendency to reduce language efforts and language means, which manifests itself especially in conversational discourse, and the activation of univerbation, necessitated the creation of a vocabulary of univerbations. Different points of view on the phenomenon of univerbation are considered and the author's vision of this phenomenon, which is the basis for the selection of linguistic facts in a dictionary, is determined. Models and derivational means of creating university stores are systematized, the main thematic groups are given, their stylistic affiliation and functioning are analyzed. The author emphasizes the stylistically reduced, colloquial nature of most of the new formations considered in the dictionary, often the presence of an emotional-evaluative component in them, and expresses an opinion about the preservation of the productivity of the model and the constant replenishment of the dictionary.

Keywords: modern Russian language, development trends, univerbation, word formation methods, dictionaries.

«Словарь универбатов современного русского языка» (Клименко Г. В., Маркова Е. М., Москва: Прометей, 2019) является первым учебным словарём универбатов современного русского языка и представляет собой словарь смешанного типа: толково-словообразовательный, в чём выражается нетради- 
ционный подход в лексикографической практике. В нём авторы преследовали цель систематизировать столь массовое в последнее время языковое явление, как универбация, захлестнувшее не только страницы газет и журналов, но и устную речь (телевидение, радиовещание, живое общение). В словаре делается попытка в учебно-ознакомительном аспекте представить слова-универбаты и их значения путём совмещения двух языковых уровней: лексического и деривационного.

В словаре выделены и собраны наиболее частотные универбаты (материал для словаря извлечён из газетно-журнальной периодики последних десятилетий, а также из Национального корпуса русского языка, использовались также данные современных толковых словарей), дана их комплексная характеристика: лексическая, словообразовательная, грамматическая, что может быть использовано в учебном процессе. Нетрадиционность и новизна работы заключается в том, что, вскрывая связь лексического и словообразовательного значения, стало возможным уточнить семантику таких специфических образований, как универбаты, проследить механизмы их образования, выявить типологические моделиих образования и использовать в качестве обучающего материала на занятиях по русскому языку как иностранному.

Словарь ориентирован прежде всего на иностранных учащихся, изучающих современный русский язык, особенно для будущих переводчиков. Так как универбаты, как правило, отсутствуют в толковых словарях, подобный опыт их отбора и систематизации может быть полезен преподавателям русского языка как неродного и как иностранного. Кроме того, материалы словаря могут быть использованы в преподавании филологических дисциплин, спецкурсов и др.

Потребность в создании данного словаря вызвана активизацией универбации и широким распространением этого явления в наши дни, вызванного усилением тенденции к экономии языковых средств. Универбаты активно продуцируются в разговорной речи, в повседневной коммуникации, поскольку именно в этих сферах закон экономии находит своё яркое выражение. Некоторые из таких дериватов проникают и в книжные стили. Тенденция к экономии, сокращению, минимизации языковых усилий и в соответствии с этим языковых средств обусловлена многими причинами, среди которых можно назвать: научно-технический прогресс, ускорение общего темпа жизни и деятельности, стремительно происходящие общественно-экономические и политические изменения, глобалистические процессы, вызывающие появление однотипных явлений в разных языках, влияние английского языка, в котором компрессионные способы образования слов являются чрезвычайно продуктивными, наконец, стремление к словомейкерству, окказиональному словообразованию, побуждающее творить новые слова по существующим моделям.

О явлении универбации в лингвистике не существует однозначного и единого мнения. Есть множество разных точек зрения на это явление: от самого широкого понимания, при котором универбация рассматривается как универсальный словообразовательный процесс, и в этом случае всякое словопроизводство приравнивается к универбизации (Кубрякова 1986; Лопатин 2003), либо как любая деривация, основанная на сокращении, усечении слова или стяжении словосочетания в однословное наименование (Маркова 2018); до более узкого, при 
котором под универбацией понимается либо совокупность разных по структуре и способу образования дериватов, так или иначе свернутых на базе словосочетаний (Янко-Триницкая 2001; Устименко 2007); либо как процесс производства суффиксальных дериватов с определёнными формантами на основе атрибутивных словосочетаний, имеющих устойчивый характер (Земская 2000; Осипова 1999; Теркулов 2010; Лукашанец 2016). Большинство исследователей всё же сходятся во мнении, что универбация представляет собой словообразовательный процесс, в результате которого продуцируются разговорные существительные, представляющие собой однословные эквиваленты в разной степени устойчивых словосочетаний, являющихся наименованиями кодифицированного литературного языка. Как правило, производящей основой неодеривата служит словосочетание: «прилагательное» + «существительное». В образованный дериват входит только основа атрибутивного компонента, тогда как определяемое существительное (или несколько существительных) подразумевается в мотивационной базе, но формально во вновь образованной единице не отражено. При этом происходит конденсация семантики словосочетания. Процесс формальной и семантической компрессии, происходящей при этом, сопровождается использованием суффиксов: частный предприниматель $\rightarrow$ частн-ик, заnасное колесо $\rightarrow$ запас-к(a). Такая трактовка универбации принята при отборе слов в данном словаре.

Структура словарной статьи включает в себя следующие компоненты. В качестве словарной единицы выступает лексема-универбат. В словах приводятся указания на произношение (ударение). В словарной статье представлены: лексическая единица (универбат), модель словообразования, его словообразовательная структура, лексическое значение, грамматические характеристики (окончание в форме родительного падежа, род существительного), даётся толкование слова и приводятся иллюстрации с источником. Например: $\boldsymbol{A в а р и ' и ̆ к а ~}$ -и, ж. Аварийная служба $+\kappa(a)$. Служба, вызываемая в случае аварии в доме (из-за воды, электричества) Кто-то спрашивал, куда подевался электрик, ктото звонил в аварийку [Ю.И. Андреева. Многоточие сборки (2009)]. В некоторых случаях, если словообразовательная формула исчерпывающе толкует универбат и не требует дополнительного толкования, не даётся лексическое значение. Например: Бесполезня́к -а, м. Бесполезное дело + як. Она открыла глаза, посмотрела на него бессмысленно - и уронила голову на колени. "Полная отключка, бесполезняк! - подумал Митя [А. Житков. Кафедра (2000)].

Наиболее продуктивным суффиксальным элементом, участвующим в механизме создания универбата является суффикс к, вместе с тем анализ нашего материала дал возможность выявить и другие форманты, используемые в этом процессе: суффиксы -нк-, -ик-/-ник-, -ил-/-илк-, -овк-/-ловк-, -ёрк-, -ок, -ак-/-як-, -янк-, -иц-, -учк-, -шк-/-ушк-/-яшк-/-ишк-, -енец-, -шин-. -ух-/юx-, -ур-, -ун-, -ач-. Многие из них, помимо разговорного характера, придают новым единицам экспрессивное, оценочное звучание. Встречаются и бессуффиксные универбаты.

В тематическом плане универбаты представляют собой разнородный пласт лексики, что объясняется продуктивностью моделей универбации практически во всех сферах общественной деятельности и коммуникации. Поэтому много- 
численны и разнообразны тематические группы подобной лексики. В разговорной речи универбаты в основном представляют собой бытовую лексику, так называемые «бытовизмы». Они входят в тематические группы «Помещение», «Дороги», «Транспорт», «Одежда», «Лекарственные средства» и др., то есть представляют собой лексические пласты, обозначающие повседневные реалии современного человека (Дозорова 2015). Пополнение этих групп происходит по мере распространения новых явлений в общественной и бытовой сферах. Например, к концу XX - началу XXI века можно отнести такие универбаты-неологизмы, как аварийка, мобильник, струйник, иифровик, наружка и др. Что касается универбатов непредметной семантики, это в основном дериваты, обозначающие процесс (кругосветка, пленаркаи т. п.) или отвлечённое понятие или явление (уголовка, неуставняк, конкретика и др.). Однако универбатов с непредметной семантикой меньше, чем производных, обозначающих конкретные объекты действительности. Помимо дериватов с предметной и процессуальноотвлечённой семантикой, активизируется производство универбов-наименований человека по профессии или роду занятий (глазник, международник и др.).

Тематические группы универбатов различны по количеству единиц, которые в них входят, что обусловлено экстралингвистическими факторами, прежде всего, социокультурными. Так, пополнение таких тематических групп, как «Интернет», «Компьютерная лексика», связано именно с возникновением новых форм коммуникации и развитием информационных технологий. Другие группы, например тематические группы «Технические устройства», «Косметические средства», в настоящее время продолжают пополняться новыми дериватами, что также объясняется социальными причинами: на их расширение оказывает влияние развитие промышленности, возникновение новых способов производства. Другие же группы более устойчивы и менее многочисленны, например, тематические группы «Части тела человека», «Пищевые продукты». Динамика социокультурной жизни вызывает появление соответствующих дериватов в номинации учебных заведений (вышка), общественных мероприятий (корпоративка/корпоратив), компьютерной или видеопродукции (материнка, лицензионка).

Стилистической особенностью универбатов является их активное функционирование в разговорной речи. Большинство универбатов относится к разговорной лексике, например: бытовка, гречка, аварийка. Некоторые из них имеют просторечный оттенок, однако многие слова уже вошли в кодифицированный литературный язык. Примером этого могут служить слова, сосуществующие со своими полными вариантами: вишневка «вишневая наливка или настойка»; кожанка «кожаная куртка или кожаное пальто»; невидилка «невидимое существо» и т. п. Наиболее распространённым из общелитературных универбатов является открытка - его связь со своим производным словосочетанием восстановлена благодаря переизданию старых открыток и конвертов, имеющих надписи «открытое письмо» и «закрытое письмо», относящихся в современном русском языке к устаревшим наименованиям.

Однако в целом универбаты связаны с разными типами дискурсов: политическим, экономическим, правовым, военным, спортивным, медицинским и т. д. Авторы словаря не ставили перед собой нормативных задач, но пытались объ- 
ективно отразить различные слои лексики: разговорную, просторечную, нейтральную, жаргонную. Столь широкий подход к нормативному аспекту обусловлен неопределённостью во многих случаях стилистического статуса слова, расхождениями в пометах имеющихся толковых словарей. Кроме того, реалии нашего времени, быстрота перемещения из одного стилистического слоя в другой также затрудняет задачу определения того или иного статуса слова.

Некоторые образования относятся к терминам, которые, однако, вошли в общее употребление и понятны носителям языка: валерьянка, щзитовидка, аскорбинка. Узкоспециальные термины не включены в состав словаря. Ряд просторечных и жаргонных универбатов включён в словник, т. к. с одной стороны, авторы преследовали цель наиболее полно представить состав современного языка, с другой стороны, руководствуясь тем, что в настоящее время налицо тенденция перемещения лексем из просторечной или жаргонной лексики в разговорную речь. В толковых нормативных словарях имеются расхождения в этом вопросе. Так, помету «просторечное» носят слова караулка, самоволка, манка, времянка и др., хотя, на наш взгляд, их уже вполне можно отнести к разговорной речи. В этом нет ничего необычного: как отмечает В.Г Костомаров, «вкус - это меняющийся идеал пользования языком соответственно характеру эпохи»1 (Костомаров 1999).

В семантическом плане большинство универбатов однозначно. Полисемия встречается редко, например: грунтовка а) «грунтовая дорога»; б) «грунтовое покрытие». Встречаются и слова-омонимы, например: коммуналка I «коммунальная квартира»; коммуналка II «коммунальные услуги»; двушка I «двухкомнатная квартира»; двушка II (уст.) «двухкопеечная монета»; микроволновка I «микроволновая антенна»; микроволновка II «микроволновая печь».

Основной аудиторией, к которой обращён его материал, являются иностранные студенты, изучающие русский язык и знакомящиеся с реалиями русской жизни и их номинациями. Данный словарь поможет студентам-иностранцам в овладении современным разговорным русским языком, что соответствует основной цели обучения русскому языку как иностранному - цели формирования коммуникативной компетенции, прежде всего в сфере бытовой коммуникации. К тому же описание в словарных статьях способов образования универбатов даст возможность иностранцам познакомиться с основными словообразовательными моделями новых языковых явлений, увидеть механизмы их создания, что будет способствовать формированию у них лингвистической компетенции.

Приведённый в словаре материал (около 600 универбатов различной тематики и структуры) свидетельствует о большом потенциале деривационных моделей универбации и о прогнозируемом пополнении литературного словарного состава русского языка новыми номинациями. С появлением инноформ, образованных путём универбации, предполагается пополнение и расширение словаря. Так, в последнее время были зафиксированы такие новые образования в русле описанной тенденции, как документалка $\longleftarrow$ докментальный фильм («Судя по откликам, это реакция тех, кто давно не смотрит ТВ и поэтому не видит, что это формат интеллигентного, умного разговора, да еще и с документалкой»), побочка $\leftarrow$ побочный эффект («У этого лекарства много побочки»), 
удаленка $\leftarrow$ удаленная работа («В связи с короновирусом многие переведены на удаленку»), иммунка $\longleftarrow$ иммунная система («Это все поднимает иммунку»), дистанциионка $\longleftarrow$ дстанциионная работа («Все вузы и школы в период пандемии перешли на дистанционку»), атипичка $\leftarrow$ атипичная пневмония («Вирус поражает легкие и развивается атипичка»), неучтенка $\leftarrow$ неучтенные деньги, незавершенка $\leftarrow$ незавершенное строительство («В области много незавершенки»), обнаженка Łобнаженная фигура («В целом, большинство оказалось не против такой «обнаженки»). Есть примеры и с другими суффиксами, демонстрирующими не только снижение стилистического регистра по сравнению с исходным двусловным наименованием, но и эмоционально-оценочный характер усеченной номинации: чрезвычайщина Ł чрезвычайная ситуация («Чрезвычайщины, конечно, нет, но мы должны принять меры»), заказуха Ł заказное дело («В том, что это отрежиссированая заказуха, сомнений нет»).

Приведенные примеры демонстрируют актуальность и растущую продуктивность универбации как способа словообразования, отражающего процесс «сворачивания» словосочетания в однословное наименование - явления, реализующего тенденцию к сокращению, усечению, минимизации языковых усилий и языковой продукции - характерной приметы нашего времени, современной языковой ситуации.

\section{Использованная литература}

Дозорова, Дарья В. «Тематические сферы употребления универбатов в современной русской речи». Вестник МГОУ (электронный журнал) 1, 2015 www. evestnik-mgou.ru.

[Dozorova, Darya V. «Tematicheskie sfery upotrebleniya univerbatov v sovremennoi russkoi rechi». Vestnik MGOU (elektronnyi zhurnal) 1, 2015. www.evestnik-mgou.ru]

Земская, Елена А. Активные процессы современного словопроизводства / Русский язык конца XX столетия (1985-1995). 2-е изд. Москва: Языки русской культуры, 2000.

[Zemskaya, Elena A. Aktivnye protsessy sovremennogo slovoproizvodstva / Russkii yazyk kontsa XX stoletiya (1985-1995). 2-e izd. Moskva: Yazyki russkoi kul'tury, 2000]

Костомаров, Виталий Г. Языковой вкус эпохи. Из наблюдений над речевой практикой масс-медиа. Санкт-Петербург, 1999.

[Kostomarov, Vitalij G. Yazykovoi vkus ehpokhi. Iz nablyudenii nad rechevoi praktikoi mass-media. Sankt-Peterburg, 1999]

Кубрякова, Елена С. Номинативный аспект речевой деятельности. Москва: Наука, 1986.

[Kubryakova, Elena S. Nominativnyi aspekt rechevoi deyatel'nosti. Moskva: Nauka, 1986]

Лопатин, Владимир В. Универбация. [В:] Ю.Н. Караулов (ред.). Русский язык: Энциклопедия. Москва: Большая Российская энциклопедия, 2003.

[Lopatin, Vladimir V. Univerbatsiya [In:] Yu.N. Karaulov (red.) Russkii yazyk: Ehntsiklopediya. Moskva: Bol'shaya Rossiiskaya ehntsiklopediya, 2003]

Лукашанец, Елена. «Методология исследований русского сленга: новые источ- 
ники» [B:] Koriakowcewa E. (red.). Współczesne językoznawstwo słowiańskie: teoria i metodologia badań. T. 2: Metody analizu i opisu jednostek leksykalnych i tekstowych. Siedlce, Academia Podlaska w Siedlcach, 2016, 51-60.

[Lukashanets, Elena. «Metodologiya issledovanii russkogo slenga: novye istochniki». [In:] Koriakowcewa E. (red.). Współczesne językoznawstwo słowiańskie: teoria i metodologia badań. T. 2: Metody analizu i opisu jednostek leksykalnych i tekstowych. Siedlce, Academia Podlaska w Siedlcach, 2016, 51-60]

Маркова, Елена М. «Глагольная универбация в свете славянского словообразования». [В:] Титаренко Е. Я. (отв. ред.). Русский язык в поликультурном мире. II Международный симпозиум (8-12 июня 2018 г.): сборник научных статей. Том 1. Симферополь: ИТ «АРИАЛ», 2018, 232-238.

[Markova, Elena M. «Glagol'naya univerbatsiya v svete slavyanskogo slovoobrazovaniya» [In:] Titarenko E.Ya (otv. red.). Russkii yazyk v polikul'turnom mire. II Mezhdunarodnyi simpozium (8-12 iyunya 2018): Sbornik nauchnykh statei. Tom 1 Simferopol': IT «ARIAL», 2018, 232-238.]

Осипова, Людмила И. Активные процессы в современном русском словообразовании: Суффиксальная универбация, усечение. Автореферат дисс... док. филол. наук. Москва: МПГУ, 1999.

[Osipova, Lyudmila I. Aktivnye protsessy v sovremennom russkom slovoobrazovanii: Suffiksal'naya univerbatsiya, usechenie. Avtoreferat diss. ... dok. filol. nauk. Moskva: MPGU, 1999]

Теркулов, Вячеслав И. «Универбализация: постановка проблемы». Ученые записки Забайкальского государственного гуманитарно-педагогического университета им. Н.Г. Чернышевского. Серия «Филология, история, востоковедение» 3, 2010 : $135-142$.

[Terkulov, Vyacheslav I. «Univerbalizatsiya: postanovka problemy». Uchenye zapiski Zabaikal'skogo gosudarstvennogo gumanitarno-pedagogicheskogo universiteta im. N.G. Chernyshevskogo. Seriya «Filologiya, istoriya, vostokovedeniE» 3, 2010: 135-142]

Устименко, Ирина А. Явление семантической конденсации в русском словообразовании: Пособие к спецкурсу. Белгород: Изд-во БелГУ, 2007.

[Ustimenko, Irina A. Yavlenie semanticheskoi kondensatsii v russkom slovoobrazovanii: Posobie k spetskursu. Belgorod: Izd-vo BeLGU, 2007]

Янко-Триницкая, Надия А. Словообразование в современном русском языке. Москва: Индрик, 2001.

[Yanko-Trinitskaya, Nadiya A. Slovoobrazovanie v sovremennom russkom yazyke. Moskva: Indrik, 2001] 
Јелена Маркова

\section{ШКОЛСКИ РЕЧНИК УНИВЕРБА У САВРЕМЕНОМ РУСКОМ ЈЕЗИКУ: НОВИНА, СТРУКТУРА, ПРИНЦИПИ ОПИСИВАЬА}

\section{Резиме}

У чланку се говори о широко распрострањеној језичкој појави у новије време-унвебацији, опште заступљеној у савременом говорном језику. «Речник универба у савременом руском језику» («Словарь универбатов современного русского языка», Клименко Г. В., Маркова Е. М., Москва: Прометей, 2019) представља први школски речник универба мешовитог типа: описно-творбеног, у чему је испољен нетрадиционални приступ у лексикографској пракси. У речнику се врши покушај да се у наставно-образовном аспекту представе речи-универби и њихова значења преко комбинације два језичка нивоа: лексичког и деривационог. У њему су представљени најфреквентнији универби и дат је њихов комплексни опис: лексички, творбени, граматички, што може бити искоришћено у наставном процесу. Нетрадиционалност и новина посла је у томе што је са откривањем везе лексичког и творбеног значења могуће прецизирати семантику посматраних облика, пропратити механизме њиховог формирања изнети на видело типолошке моделе и искористити их у својству наставног материјала у практичној настави руског као страног језика.

Покретачка снага универбације јесте јачање тенденције ка уштеди језичких напора и у складу са тим сажимање, минимизација језичких средстава. Аутор разматра различита гледишта на суштину и закључује, да универбација представља творбени процес, чији је резултат продуковање говорних именица, које представљају еквиваленте од једне речи у устаљеним синтагмама различитог степена, који представљају номинације кодификованог књижевног језика. Притом долази до семантичке кондензације синтагми. Разматрају се основна творбена средства стварања номинација од једне речи и тематске групе, којима они припадају.

У закључку аутор скреће пажњу на отворени карактер речника, уз претпоставке за његово непрестано допуњавање у складу са појављивањем нових облика посматраног начина творбе. У својству доказа наводи се неколико нових творевина, које су се појавиле у руском језику током последњих неколико месеци.

Кључне речи: савремени руски језик, тенденције развоја, начини творбе, универбација, речници. 